\title{
Cushing's syndrome: update on signs, symptoms and biochemical screening
}

\section{Lynnette K Nieman}

The Eunice Kennedy Shriver National Institute of Child Health and Human Development, National Institutes of Health, Building 10, CRC, 1 East, Rm 1-3140, 10 Center Dr, MSC 1109, Bethesda, Maryland 20892-1109, USA
Correspondence should be addressed to L K Nieman

Email

NiemanL@nih.gov

\begin{abstract}
Endogenous pathologic hypercortisolism, or Cushing's syndrome, is associated with poor quality of life, morbidity, and increased mortality. Early diagnosis may mitigate against this natural history of the disorder. The clinical presentation of Cushing's syndrome varies, in part related to the extent and duration of cortisol excess. When hypercortisolism is severe, its signs and symptoms are unmistakable. However, most of the signs and symptoms of Cushing's syndrome are common in the general population (e.g., hypertension and weight gain) and not all are present in every patient. In addition to classical features of glucocorticoid excess, such as proximal muscle weakness and wide purple striae, patients may present with the associated comorbidities that are caused by hypercortisolism. These include cardiovascular disease, thromboembolic disease, psychiatric and cognitive deficits, and infections. As a result, internists and generalists must consider Cushing's syndrome as a cause, and endocrinologists should search for and treat these comorbidities. Recommended tests to screen for Cushing's syndrome include $1 \mathrm{mg}$ dexamethasone suppression, urine free cortisol, and late night salivary cortisol. These may be slightly elevated in patients with physiologic hypercortisolism, which should be excluded, along with exogenous glucocorticoid use. Each screening test has caveats and the choice of tests should be individualized based on each patient's characteristics and lifestyle. The objective of this review is to update the readership on the clinical and biochemical features of Cushing's syndrome that are useful when evaluating patients for this diagnosis.
\end{abstract}

\section{Signs and symptoms of Cushing's syndrome}

Cushing's syndrome is caused by chronic exposure to excess cortisol. Its associated comorbidities contribute to a decreased quality of life (1) and an increased standardized mortality rate compared to the general population $(2,3,4,5)$. Although some studies show an increased mortality regardless of remission status (4), most studies indicate that an early diagnosis is important to reduce mortality and morbidity $(6,7)$. Detection relies first on clinical suspicion and then on biochemical confirmation.

The clinical presentation of Cushing's syndrome varies, in part related to the extent and duration of cortisol excess. When hypercortisolism is severe, its signs

\section{Invited Author's profile}

Dr L K Nieman is a Senior Investigator at the National Institutes of Health (NIH) Clinical Research Center and head of the Endocrine Consult service. She also directs the Office of Human Subjects Research Protections for intramural NIH. From 1991 to 2001 she served as the clinical director of intramural National Institute of Child Health and Human Development (NICHD), overseeing the clinical care of the institute's patients and ensuring compliance with human subjects' research regulations. Dr L K Nieman is an active clinical investigator, with special expertise in the disorders of hypercortisolism.

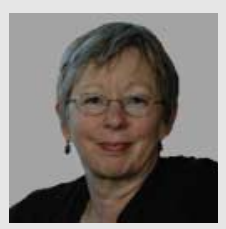

(C) 2015 European Society of Endocrinology Printed in Great Britain Published by Bioscientifica Ltd.
This article is adapted from work presented at IMPROCUSH-1, 12-14 October 2014. The meeting was supported by the European Science Foundation, Deutsche

Forschungsgemeinschaft, Carl Friedrich von Siemens Stiftung, European Neuroendo-

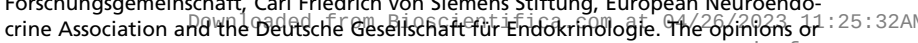
views expressed in this article are those of the authors, and do not necessarily reflecte access

the opinions or recommendations of the supporters of the symposium. 
and symptoms are unmistakable. In particular, proximal muscle weakness, wasting of the extremities with increased fat in the abdomen, torso and face, and wide purple striae, suggest marked hypercortisolism. However, most of the signs and symptoms of Cushing's syndrome are common in the general population (Table 1), and not all are present in every patient. As a result, patients with mild or cyclic disease may not present in the more classical way. (A discussion of so-called subclinical Cushing's syndrome is beyond the scope of this article.)

Because of the variety in presentation, patients are often referred to subspecialists for complaints that are gynecologic (oligomenorrhea, hirsutism, infertility), dermatologic (red facial skin, poor wound healing, striae, acne), orthopedic/rheumatologic (fractures, low bone mineral density), metabolic (hypertension, diabetes, dyslipidemia), infectious (community acquired and infections seen with immunosuppression (8)), cardiovascular (stroke, myocardial infarction, pulmonary embolism (9)), neurologic (decreased strength, headaches, decreased memory and cognition), psychiatric (depression, anxiety, mood change), and nonspecific (fatigue, backache, and weight gain). Because of this, early detection may not occur unless the specialist considers other features not related to the referral question. It is important to screen for the associated comorbidities in patients with the disorder. Newer tests such as cardiac MRI (to study structure/function) and CT (to evaluate atherosclerosis) may be useful in the future but have not yet been validated fully $(10,11)$. It is essential to treat comorbidities, both while trying to establish the diagnosis and beyond.

One might not suspect the diagnosis in milder cases based on a single visit without consideration of a complete history. However, Cushing's syndrome tends to progress over time so that an accumulation of relevant features over

Table 1 Signs and symptoms of Cushing's syndrome.

\begin{tabular}{|c|c|}
\hline More common & Less common \\
\hline Decreased libido & $\begin{array}{l}\text { EKG abnormalities or } \\
\text { atherosclerosis }\end{array}$ \\
\hline Obesity/weight gain & Striae \\
\hline Plethora & Edema \\
\hline Round face & Proximal muscle weakness \\
\hline Menstrual changes & Osteopenia or fracture \\
\hline Hirsutism & Headache \\
\hline Hypertension & Backache \\
\hline Ecchymoses & Recurrent infections \\
\hline Lethargy, depression & Abdominal pain \\
\hline Dorsal fat pad & Acne \\
\hline Anormal glucose tolerance & Female balding \\
\hline
\end{tabular}

time often leads to the diagnosis; previous photographs may help identify this progression. One recent study showed that face classification software correctly classified nearly all of the patients (85\%) and controls (95\%) using facial photographs. Further prospective research in patients suspected of having Cushing's syndrome is needed to validate this tool (12).

A few recent studies compared the prevalence of various features in patients with established Cushing's syndrome and those suspected to have the condition in whom it was excluded. The latter group is often referred to as having 'pseudo-Cushing's syndrome' because they may have clinical features compatible with the syndrome, and sometimes biochemical features, but do not have endogenous pathologic hypercortisolism. In the first study, 32 patients with Cushing's syndrome were compared to 23 with pseudo-Cushing's syndrome (13). Easy bruising and osteoporosis were more common in patients with Cushing's syndrome but polycystic ovary syndrome was more common in those with pseudoCushing's syndrome. By contrast, the frequency of many features of Cushing's syndrome were similar in both groups, including diabetes, hypertension, acne, hirsutism, and menstrual disorders, probably reflecting the features that prompted evaluation.

In a second study, 53 of 73 patients were ultimately found to have Cushing's disease, while the remaining 20 were classified as having pseudo-Cushing's syndrome, despite having elevated urine free cortisol (UFC) and/or an abnormal response to dexamethasone, $1 \mathrm{mg}$ (14). Among the latter group, more than half had a BMI> $30 \mathrm{~kg} / \mathrm{m}^{2}$ and moon facies or increased dorsocervical fat. Myopathy, hirsutism, acne, and osteoporosis were present in $<20 \%$.

Mood and cognitive changes have long been recognized as important clues to the presence of Cushing's syndrome (15). Chief among these is the development of a more labile mood, with irritability and expressions of anger that may seem relatively unprovoked. Classically, short-term memory is impaired, as is mental calculation these can and should be evaluated at the bedside by history and recall of three objects and serial seven subtractions. Problems with sleep-onset and sleep-maintaining insomnia, as well as early morning awakening are common. General psychiatric functioning may deteriorate - often along the lines of the pre-morbid personality - e.g., the patient with occasional depression may develop severe chronic depression when hypercortisolemic. 


\section{Biochemical diagnosis of Cushing's syndrome}

While biochemical features of hypercortisolism may firmly establish the diagnosis, a variety of conditions are associated with mild physiologic hypercortisolism in the absence of Cushing's syndrome, as shown in Table 2. Cushing's syndrome may be suspected in these patients because of the presence of features that are common in the absence of Cushing's syndrome, such as weight gain, hypertension, and mood changes. As noted above, such patients are often referred to as having pseudo-Cushing's syndrome because they do not have the condition despite having mild hypercortisolism and compatible features. One approach to these patients is to wait to test until the condition has resolved (acute illness), is adequately treated (depression), or is abandoned (daily strenuous exercise), in which case the mild hypercortisolism may resolve as well.

The Endocrine Society's Clinical Practice Guideline for the diagnosis of Cushing's syndrome recommends that exogenous administration/ingestion of glucocorticoids be considered and excluded before performing screening tests. The guideline recommends using two of three screening tests to establish the diagnosis: UFC, late night salivary cortisol, or $1 \mathrm{mg}$ dexamethasone suppression test (16). It is important to individualize the choice of the test(s) and to perform more than one of the cortisol tests, if they are chosen, to minimize the effect of day-to-day variations.

A number of factors influence the outcome of screening tests for Cushing's syndrome. Common among them are the need for laboratory testing and the requirement for accuracy and precision at low quantifiable hormone levels. These issues will be discussed in conjunction with each test.

Table 2 Physiologic hypercortisolism.

Some clinical features of CS may be present

Pregnancy

Depression and other psychiatric conditions $(36,37)$

Alcohol dependence

Glucocorticoid resistance

Morbid obesity

Poorly controlled diabetes mellitus

Unlikely to have any clinical features of CS

Physical stress (hospitalization, surgery, pain) (38)

Malnutrition, anorexia nervosa

Intense chronic exercise

Hypothalamic amenorrhea

CBG excess (increased serum but not UFC)

\section{Dexamethasone suppression test}

The $1 \mathrm{mg}$ overnight dexamethasone suppression test interrogates whether glucocorticoid negative feedback is normal. This outpatient test involves administration of dexamethasone, $1 \mathrm{mg}$ by mouth, between 2300 and $00 \mathrm{~h}$, and the measurement of serum cortisol between 0800 and $0900 \mathrm{~h}$ the following morning. The results are normal if the cortisol is $<1.8 \mu \mathrm{g} / \mathrm{dl}(50 \mathrm{nmol} / \mathrm{l})$. (Higher values are associated with a lack of appropriate negative feedback in Cushing's syndrome patients.) This value is very close to the functional detection limit of some assays, so that inherent assay variability might account for an 'abnormal' result close to the cutoff point.

Falsely abnormal results occur in a variety of settings. Women taking oral estrogens may have an increase in corticosteroid-binding globulin (CBG), which in turn increases total cortisol, potentially leading to abnormal results (17). The measurement of salivary cortisol was not found to be helpful in one study of 19 women on oral contraceptives; another study of 21 such women found improved specificity compared to the use of serum cortisol as an endpoint ( $91 \%$ vs $62 \%$ ). However, each of these was worse than the corresponding specificity of healthy control individuals not taking oral contraceptives (98\% for each) (18). Thus, salivary cortisol after dexamethasone may be a better outcome measure than serum cortisol. However, its performance has not been compared to that of other screening tests in women taking oral estrogens.

Medications may accelerate or impair dexamethasone metabolism (http://medicine.iupui.edu/flockhart/table. htm) potentially causing falsely abnormal or normal results respectively (19). Dexamethasone is metabolized by the CYP3A4 complex, which is stimulated or inhibited by many commonly used drugs. Valassi et al. (20) studied whether medication use altered the results of the test. They found that those patients who did not have Cushing's syndrome but were taking medications were more likely to have an abnormal test result that those who were medication free (specificity $70 \%$ vs $96 \%$ respectively, $P=0.014)$. Conversely, in another study, up to $8 \%$ of patients with Cushing's disease had a normal response (i.e., suppression) to the low-dose dexamethasone suppression test (21). Measurement of dexamethasone levels can help identify potential abnormal clearance of dexamethasone but has not come into general practice (22).

\section{Urine free cortisol}

UFC reflects the integrated tissue exposure to free cortisol over $24 \mathrm{~h}$ and so provides a unique perspective on 
glucocorticoid physiology that is different from the other two tests. The choice of the assay technique appears to affect whether a patient with mild Cushing's syndrome will have a normal or abnormal UFC $(23,24)$. This is explained by cross-reactivity with cortisol precursors and metabolites in immunoassays, which is not present in the structurally based assays such as high performance liquid chromatography or tandem mass spectrometry (25). As a result, a patient may have a normal result in the structurally based assay but an abnormal result in the immunoassay. The pre-test probability (26) may influence the decision to use UFC, with a low pre-test probability suggesting this choice.

As mentioned earlier, the pseudo-Cushing states are associated with a physiologic increase in UFC; for such individuals, other screening tests may be preferable. Caveats to the test include its inconvenience, with the attendant possibility of under- or over-collection. For this reason, the measurement of both creatinine and volume are helpful to assess completeness, and patients must be able to comply with the correct collection procedures. UFC is falsely raised when the volume is $>51$ (27) and falsely low when glomerular filtration rate falls (28).

More than one UFC measurement is needed to avoid false negative results, detect cyclic hypercortisolism, and validate the diagnosis, as patients with Cushing's disease may have quite variable UFCs (29), ranging from normal to severely elevated values in the same patient.

\section{Salivary cortisol}

Serum and salivary cortisol reach a nadir just after sleep initiation (30); this entrained circadian phenomenon is disrupted when sleep occurs at different times of the day such as with shift work or travel to a new time zone. Patients with Cushing's syndrome lose this diurnal nadir and have increased serum and salivary cortisol values at bedtime compared with obese and pseudo-Cushing's patients $(23,31)$. Salivary cortisol has the advantage of allowing for in-home collection using a salivette (a cotton pledget in a plastic tube); because cortisol is thermally stable at room temperature, the collection can be mailed to a laboratory for analysis. One caveat for salivary cortisol is that it increases with age, hypertension, and diabetes (32), so that its use in such patients may give a falsely positive result. Additionally, immunoassays may increase the false positive rate (33), potentially because of crossreactivity with cortisone, which salivary glands convert from cortisol via 11ß-hydroxysteroid dehydrogenase type 2 (34). A major advantage of salivary cortisol is that it tends to be abnormal when UFC (measured by structural assays) is normal or only mildly elevated in patients with proven Cushing's syndrome $(8,19)$.

\section{A Cushing's syndrome index}

Nugent et al. (35) advanced this idea in 1964, stating 'In the differential diagnosis ... [of Cushing's syndrome], the physician uses clinical signs and simple laboratory data in addition to information ... from past experiences to make a decision concerning the probability of the diagnosis'. The authors developed a Bayesian equation using the incidence of signs and symptoms of Cushing's syndrome in 211 patients. They then used the equation to calculate the probability of Cushing's syndrome in 111 patients. The clinical features included osteoporosis, central/generalized obesity, weakness, bruising/acne, plethora, colored striae, edema, hirsutism, oligomenorrhea, headache, abnormal glucose tolerance, age $<35$ years, diastolic blood pressure $>105 \mathrm{mmHg}$, red blood cell volume $>49 \mathrm{fl}$, and serum potassium $<3.6 \mathrm{mEq} / \mathrm{l}$. This approach returned a 'confident' diagnosis of Cushing's syndrome in nine out of 38 patients with the disorder, and the exclusion of the syndrome in 45 out of 93 without the disorder.

Unfortunately, the results of this Bayesian analysis do not give high positive (16\%) and negative (61\%) predictive values. However, the concept of an 'index' deserves to be reevaluated with current data.

\section{Declaration of interest}

The authors declare that there is no conflict of interest that could be perceived as prejudicing the impartiality of the review.

\section{Funding}

This work was supported by the Eunice Kennedy Shriver National Institute of Child Health and Human Development, National Institutes of Health, Bethesda, MD 20892-1109, USA.

\footnotetext{
Acknowledgements

This paper forms part of a special issue of European Journal of Endocrinology on Cushing's syndrome. This article is adapted from work presented at the IMPROCUSH-1: Improving Outcome of Cushing's Syndrome symposium, 12-14 October 2014. The meeting was supported by the European Science Foundation, Deutsche Forschungsgemeinschaft, Carl Friedrich von Siemens Stiftung, European Neuroendocrine Association and the Deutsche Gesellschaft für Endokrinologie. The opinions or views expressed in this special issue are those of the authors, and do not necessarily reflect the opinions or recommendations of the European Science Foundation, Deutsche Forschungsgemeinschaft, Carl Friedrich von Siemens Stiftung, European Neuroendocrine Association and the Deutsche Gesellschaft fur Endokrinologie.
} 


\section{References}

1 Lindsay JR, Nansel T, Baid S, Gumowski J \& Nieman LK. Long-term impaired quality of life in Cushing's syndrome despite initial improvement after surgical remission. Journal of Clinical Endocrinology and Metabolism 200691 447-453. (doi:10.1210/jc.2005-1058)

2 Bolland MJ, Holdaway IM, Berkeley JE, Lim S, Dransfield WJ, Conaglen JV, Croxson MS, Gamble GD, Hunt PJ \& Toomath RJ. Mortality and morbidity in Cushing's syndrome in New Zealand. Clinical Endocrinology 201175 436-442. (doi:10.1111/j.1365-2265. 2011.04124.x)

3 van Haalen FM, Broersen LH, Jorgensen JO, Pereira AM \& Dekkers OM. Management of endocrine disease: mortality remains increased in Cushing's disease despite biochemical remission: a systematic review and meta-analysis. European Journal of Endocrinology/European Federation of Endocrine Societies 2015172 R143-R149. (doi:10.1530/EJE-14-0556)

4 Ntali G, Asimakopoulou A, Siamatras T, Komninos J, Vassiliadi D, Tzanela M, Tsagarakis S, Grossman AB, Wass JA \& Karavitaki N. Mortality in Cushing's syndrome: systematic analysis of a large series with prolonged follow-up. European Journal of Endocrinology/ European Federation of Endocrine Societies 2013169 715-723. (doi:10.1530/EJE-13-0569)

5 Lambert JK, Goldberg L, Fayngold S, Kostadinov J, Post KD \& Geer EB. Predictors of mortality and long-term outcomes in treated Cushing's disease: a study of 346 patients. Journal of Clinical Endocrinology and Metabolism 201398 1022-1030. (doi:10.1210/jc.2012-2893)

6 Hammer GD, Tyrrell JB, Lamborn KR, Applebury CB, Hannegan ET, Bell S, Rahl R, Lu A \& Wilson CB. Transsphenoidal microsurgery for Cushing's disease: initial outcome and long-term results. Journal of Clinical Endocrinology and Metabolism 200489 6348-6357. (doi:10.1210/ jc.2003-032180)

7 Swearingen B, Biller BM, Barker FG II, Katznelson L, Grinspoon S, Klibanski A \& Zervas NT. Long-term mortality after transsphenoidal surgery for Cushing disease. Annals of Internal Medicine 1999130 821-824. (doi:10.7326/0003-4819-130-10-199905180-00015)

8 Aucott JN. Glucocorticoids and infection. Endocrinology and Metabolism Clinics of North America 199423 655-670.

9 van der Pas R, Leebeek FW, Hofland LJ, de Herder WW \& Feelders RA. Hypercoagulability in Cushing's syndrome: prevalence, pathogenesis and treatment. Clinical Endocrinology 201378 481-488. (doi:10.1111/ cen.12094)

10 Kamenický P, Redheuil A, Roux C, Salenave S, Kachenoura N, Raissouni Z, Macron L, Guignat L, Jublanc C, Azarine A et al. Cardiac structure and function in Cushing's syndrome: a cardiac magnetic resonance imaging study. Journal of Clinical Endocrinology and Metabolism 201499 E2144-E2153. (doi:10.1210/jc.2014-1783)

11 Neary NM, Booker OJ, Abel BS, Matta JR, Muldoon N, Sinaii N, Pettigrew RI, Nieman LK \& Gharib AM. Hypercortisolism is associated with increased coronary arterial atherosclerosis: analysis of noninvasive coronary angiography using multidetector computerized tomography. Journal of Clinical Endocrinology and Metabolism 201398 2045-2052. (doi:10.1210/jc.2012-3754)

12 Kosilek RP, Schopohl J, Grunke M, Reincke M, Dimopoulou C, Stalla GK, Würtz RP, Lammert A, Günther M \& Schneider HJ. Automatic face classification of Cushing's syndrome in women - a novel screening approach. Experimental and Clinical Endocrinology \& Diabetes 2013121 561-564. (doi:10.1055/s-0033-1349124)

13 Pecori Giraldi F, Pivonello R, Ambrogio AG, De Martino MC, De Martin M, Scacchi M, Colao A, Toja PM, Lombardi G \& Cavagnini F. The dexamethasone-suppressed corticotropin-releasing hormone stimulation test and the desmopressin test to distinguish Cushing's syndrome from pseudo-Cushing's states. Clinical Endocrinology $2007 \mathbf{6 6}$ 251-257. (doi:10.1111/j.1365-2265.2006.02717.x)

14 Alwani RA, Schmit Jongbloed LW, de Jong FH, van der Lely AJ, de Herder WW \& Feelders RA. Differentiating between Cushing's disease and pseudo-Cushing's syndrome: comparison of four tests. European Journal of Endocrinology/European Federation of Endocrine Societies 2014170 477-486. (doi:10.1530/EJE-13-0702)

15 Starkman MN \& Schteingart DE. Neuropsychiatric manifestations of patients with Cushing's syndrome. Relationship to cortisol and adrenocorticotropic hormone levels. Archives of Internal Medicine 1981 141 215-219. (doi:10.1001/archinte.1981.00340020077021)

16 Nieman LK, Biller BM, Findling JW, Newell-Price J, Savage MO, Stewart PM $\&$ Montori VM. The diagnosis of Cushing's syndrome: an Endocrine Society Clinical Practice Guideline. Journal of Clinical Endocrinology and Metabolism 200893 1526-1540. (doi:10.1210/jc.2008-0125)

17 Nickelsen T, Lissner W \& Schoffling K. The dexamethasone suppression test and long-term contraceptive treatment: measurement of ACTH or salivary cortisol does not improve the reliability of the test. Experimental and Clinical Endocrinology 198994 275-280. (doi:10.1055/s-0029-1210910)

18 Manetti L, Rossi G, Grasso L, Raffaelli V, Scattina I, Del Sarto S, Cosottini M, Iannelli A, Gasperi M, Bogazzi F et al. Usefulness of salivary cortisol in the diagnosis of hypercortisolism: comparison with serum and urinary cortisol. European Journal of Endocrinology/European Federation of Endocrine Societies 2013168 315-321. (doi:10.1530/EJE-12-0685)

19 Kyriazopouloub V \& Vagenakis AG. Abnormal overnight dexamethasone suppression test in subjects receiving rifampicin therapy. Journal of Clinical Endocrinology and Metabolism 199275 315-317. (doi:10.1210/ jcem.75.1.1619024)

20 Valassi E, Swearingen B, Lee H, Nachtigall LB, Donoho DA, Klibanski A $\&$ Biller BM. Concomitant medication use can confound interpretation of the combined dexamethasone-corticotropin releasing hormone test in Cushing's syndrome. Journal of Clinical Endocrinology and Metabolism 200994 4851-4859. (doi:10.1210/jc.2009-1500)

21 Findling JW, Raff H \& Aron DC. The low-dose dexamethasone suppression test: a reevaluation in patients with Cushing's syndrome. Journal of Clinical Endocrinology and Metabolism 200489 1222-1226. (doi:10.1210/jc.2003-030207)

22 Meikle AW. Dexamethasone suppression tests: usefulness of simultaneous measurement of plasma cortisol and dexamethasone. Clinical Endocrinology 198216 401-408. (doi:10.1111/j.1365-2265.1982.tb00733.x)

23 Kidambi S, Raff H \& Findling JW. Limitations of nocturnal salivary cortisol and urine free cortisol in the diagnosis of mild Cushing's syndrome. European Journal of Endocrinology/European Federation of Endocrine Societies 2007157 725-731. (doi:10.1530/EJE-07-0424)

24 Elias PC, Martinez EZ, Barone BF, Mermejo LM, Castro M \& Moreira AC. Late-night salivary cortisol has a better performance than urinary free cortisol in the diagnosis of Cushing's syndrome. Journal of Clinical Endocrinology and Metabolism 201499 2045-2051. (doi:10.1210/ jc.2013-4262)

25 Raff H, Auchus RJ, Findling JW \& Nieman LK. Urine free cortisol in the diagnosis of Cushing's syndrome: is it worth doing and, if so, how? Journal of Clinical Endocrinology and Metabolism 2015100 395-397. (doi:10.1210/jc.2014-3766)

26 Elamin MB, Murad MH, Mullan R, Erickson D, Harris K, Nadeem S, Ennis R, Erwin PJ \& Montori VM. Accuracy of diagnostic tests for Cushing syndrome: a systematic review and meta-analyses. Journal of Clinical Endocrinology and Metabolism 200893 1553-1562. (doi:10.1210/ jc.2008-0139)

27 Mericq MV \& Cutler GB Jr. High fluid intake increases urine free cortisol excretion in normal subjects. Journal of Clinical Endocrinology and Metabolism 199883 682-684. (doi:10.1210/jcem.83.2.4555)

28 Chan KC, Lit LC, Law EL, Tai MH, Yung CU, Chan MH \& Lam CW. Diminished urinary free cortisol excretion in patients with moderate and severe renal impairment. Clinical Chemistry 200450 757-759. (doi:10.1373/clinchem.2003.029934)

29 Petersenn S, Newell-Price J, Findling JW, Gu F, Maldonado M, Sen K, Salgado LR, Colao A, Biller BM \& Pasireotide B2305 Study Group . High variability in baseline urinary free cortisol values in patients with Cushing's disease. Clinical Endocrinology 201480 261-269. (doi:10.1111/ cen.12259) 
30 Krieger DT, Allen W, Rizzo F \& Krieger HP. Characterization of the normal temporal pattern of plasma corticosteroid levels. Journal of Clinical Endocrinology and Metabolism 197132 266-284. (doi:10.1210/ jcem-32-2-266)

31 Putignano P, Toja P, Dubini A, Pecori Giraldi F, Corsello SM \& Cavagnini F. Midnight salivary cortisol versus urinary free and midnight serum cortisol as screening tests for Cushing's syndrome. Journal of Clinical Endocrinology and Metabolism 200388 4153-4157. (doi:10.1210/jc.2003-030312)

32 Liu H, Bravata DM, Cabaccan J, Raff H \& Ryzen E. Elevated latenight salivary cortisol levels in elderly male type 2 diabetic veterans. Clinical Endocrinology 200563 642-649. (doi:10.1111/j.1365-2265. 2005.02395.x)

33 Baid SK, Sinaii N, Wade M, Rubino D \& Nieman LK. Radioimmunoassay and tandem mass spectrometry measurement of bedtime salivary cortisol levels: a comparison of assays to establish hypercortisolism. Journal of Clinical Endocrinology and Metabolism 200792 3102-3107. (doi:10.1210/jc.2006-2861)
34 Smith RE, Maguire JA, Stein-Oakley AN, Sasano H, Takahashi K, Fukushima K \& Krozowski ZS. Localization of 11ß-hydroxysteroid dehydrogenase type II in human epithelial tissues. Journal of Clinical Endocrinology and Metabolism 199681 3244-3248. (doi:10.1210/jcem. 81.9.8784076)

35 Nugent CA, Warner HR, Dunn JT \& Tyler FH. Probability theory in the diagnosis of Cushing's syndrome. Journal of Clinical Endocrinology and Metabolism 196424 621-627. (doi:10.1210/jcem-24-7-621)

36 Butler PW \& Besser GM. Pituitary-adrenal function in severe depressive illness. Lancet 19681 1234-1236. (doi:10.1016/S01406736(68)91927-2)

37 Pfohl B, Sherman B, Schlechte J \& Stone R. Pituitary-adrenal axis rhythm disturbances in psychiatric depression. Archives of General Psychiatry 1985 42 897-903. (doi:10.1001/archpsyc.1985.01790320069009)

38 Ross RJ, Miell JP, Holly JM, Maheshwari H, Norman M, Abdulla AF \& Buchanan CR. Levels of GH binding activity, IGFBP-1, insulin, blood glucose and cortisol in intensive care patients. Clinical Endocrinology 199135 361-367. (doi:10.1111/j.1365-2265.1991.tb03549.x)

Received 5 May 2015

Revised version received 29 May 2015

Accepted 10 June 2015 